\title{
ESTRUTURA DA VEGETAÇÃO ARBÓREA DE UM REMANESCENTE ECOTONAL URBANO FLORESTA-SAVANA NO PARQUE DO SABIÁ, EM UBERLÂNDIA, MG ${ }^{1}$
}

\author{
Frederico Augusto Guimarães Guilherme² e Jimi Naoki Nakajima ${ }^{3}$
}

\begin{abstract}
RESUMO - Neste estudo, avaliou-se a estrutura do componente arbóreo de manchas de vegetação correspondentes à Floresta Estacional Semidecidual e dois cerradões, inseridas em um remanescente urbano composto também por uma mancha de mata de brejo. O levantamento compreendeu 1,32 ha, onde todos os indivíduos com perímetro à altura do peito $\geq 5 \mathrm{~cm}$ foram amostrados. Registraram-se 141 espécies, distribuídas em 46 famílias botânicas, com diversidade de Shannon de 3,99. Fabaceae apresentou a maior riqueza de espécies no levantamento, corroborando o padrão encontrado em outros estudos sobre o bioma Cerrado. Maprounea guianensis teve os maiores valores relativos de densidade, freqüência e dominância no remanescente. A floresta estacional apresentou a maior riqueza florística e espécies características dessa formação, em comparação com demais pesquisas. Hirtella glandulosa apresentou o maior valor de importância no cerradão 2, o que evidencia a existência de um solo distrófico nessa fisionomia. Características estruturais similares entre o cerradão 2 e a floresta estacional e diversidade florística significativamente maior no cerradão 2 do que no cerradão 1 , além da presença de espécies típicas de matas de brejo e floresta estacional no cerradão 2, evidenciavam áreas de transição no remanescente. No cerradão 1 foram registrados poucos indivíduos arbóreos nas menores classes de diâmetro. Isso provavelmente se deva às perturbações antrópicas constantes e variadas, indicando a necessidade de ações preventivas para a conservação e manejo desse patrimônio biológico.
\end{abstract}

Palavras-chave: Áreas de transição, cerradão, fitossociologia, floresta estacional e parque municipal.

\section{TREE VEGETATION STRUCTURE IN AN URBAN FOREST-SAVANNA ECOTONE REMNANT, SOUTHEASTERN BRAZIL}

\begin{abstract}
The study evaluated the tree component structure of vegetation fragments consisted of semideciduous forest, two woody savannas (cerradão), inserted in an urban forest remnant, also consisting of a fragment of swamp forest. The survey comprised 1.32 hectares, where all trees with $\geq 5 \mathrm{~cm}$ perimeter at breast height were recorded. A total of 141 species distributed in 46 botanical families with Shannon diversity index of 3.99 were recorded. Fabaceae showed the greatest species richness in the survey, corroborating the pattern found in other studies on the Cerrado Biome. Maprounea guianensis had the largest density, frequency and dominance relative values in the remnant. The semideciduous forest presented the largest floristic richness and characteristic species of that formation when compared with other studies. Hirtella glandulosa showed the largest importance value in the cerradão 2, suggesting the existence of a dystrophic soil in this physiognomy. The similar structural characteristics between cerradão 2 and semideciduous forest, tree species diversity significantly larger in cerradão 2 than in cerradão 1, besides the presence of typical species of swamp forests and semideciduous forest in cerradão 2 confirm the occurrence of transition areas in the remnant. Few individuals were recorded in the smallest diameter classes in cerradão 1. Continuous and varied human disturbances probably are responsible for this, indicating the need for conservation and management preventive actions of this biological patrimony.
\end{abstract}

Keywords: Transition areas, woody savanna, phytosociology, semideciduous forest, and municipal park.

\footnotetext{
${ }^{1}$ Recebido em 02.06.2006 e aceito para publicação em 13.10.2006.

${ }^{2}$ Universidade Federal de Goiás - Campus de Jataí, 7501-615 Jataí,GO. E-mail:<fredericoagg@ gmail.com>.

${ }^{3}$ Universidade Federal de Uberlândia - Instituto de Biologia. Cx.p.593, 38400-902 Uberlândia, MG.
} 


\section{INTRODUÇÃO}

A relação entre o decréscimo no número de espécies arbóreas e a redução e isolamento de remanescentes florestais nos trópicos é bem documentada (LAURANCE e BIERREGAARD, 1997; HILL e CURRAN, 2003). Portanto, nas regiões onde os processos de fragmentação se iniciaram há décadas, perturbações antrópicas constantes representam importante ameaça à biodiversidade (VIANA e PINHEIRO, 1998). Nessa perspectiva, os "habitats" fragmentados devem corresponder à situação-padrão no futuro, sendo necessárias ações de conservação e manejo do ambiente para evitar a erosão da diversidade biológica.

O avanço acelerado da agropecuária e dos centros urbanos são os fatores responsáveis por essa deterioração das áreas naturais. Esses centros urbanos nem sempre se desenvolvem seguindo planejamentos adequados, levando à antropização severa ou, ainda, à destruição total de quase todas as áreas naturais (DISLICH e PIVELLO, 2002).

Os remanescentes vegetais urbanos podem minimizar problemas em cidades caracterizadas por rápido e recente desenvolvimento como poluição do ar e da água, impermeabilização do solo e elevação da temperatura (DISLICH e PIVELLO, 2002). Podem funcionar como excelente local para o turismo ecológico e também como abrigo para a fauna, além de manter o patrimônio fitogenético nativo.

Inseridas no bioma Cerrado, as formações savânicas do Triângulo Mineiro apresentam bom exemplo do processo de fragmentação. Atualmente, seus remanescentes estão representados por fragmentos pequenos e isolados, imersos numa paisagem dominada pela agricultura e centros urbanos. Localizado no perímetro urbano, o Parque do Sabiá tem papel importante para a cidade de Uberlândia, MG, pois possui em torno de 35 hectares de áreas florestadas com fisionomias características do bioma Cerrado (GUILHERME et al., 1998).

Estudos recentes revelam que a vegetação do Cerrado apresenta heterogeneidade entre áreas (FURLEY, 1999; BORGES e SHEPHERD, 2005), caracterizada pelo gradiente savana-floresta com associação particular de espécies (GUIMARÃES et al., 2001; GOMES et al., 2004). Essa heterogeneidade geralmente está condicionada à natureza geológica e geomorfológica (COLE, 1992), as quais geram diferenças fisionômicas, florísticas e estruturais em resposta às variações edáficas reinantes, como profundidade e umidade do solo e regimes de flutuação do lençol freático (FURLEY e RATTER, 1988; GUIMARÃES et al., 2001). As regiões de transição savana-floresta correspondem a um mosaico de aproximadamente $24 \%$ do bioma Cerrado (SILVA e BATES, 2002). Smith et al. (1997) sugerem que esses ecótonos entre dois ou mais tipos de vegetação distintos são uma importante área de especiação, as quais devem se inserir em programas de conservação, mantendo a biodiversidade desses "habitats".

Nesse contexto, este estudo teve o objetivo de analisar a estrutura do componente arbóreo em manchas de floresta estacional semidecidual e dois cerradões no Parque do Sabiá, por meio de levantamento fitossociológico, visando fornecer subsídios necessários a ações de conservação e manejo. Diferenças nas características estruturais das áreas de transição entre manchas e pressões antrópicas sobre a vegetação do remanescente florestal têm sido discutidas.

\section{MATERIAL E MÉTODOS}

\section{1. Área de estudo}

O estudo foi conduzido no Parque Municipal do Sabiá, localizado no perímetro urbano de Uberlândia, MG (18 54'52'S; 48 14'02'), com 35 hectares ocupados por remanescentes de vegetação nativa, de um total de 185 hectares. A altitude varia em torno de $890 \mathrm{~m}$ do nível do mar e possui um clima sazonal com duas estações bem definidas, uma com verão quente e chuvoso, principalmente dezembro e janeiro; e outra com inverno frio e seco, principalmente junho e julho. A precipitação e as temperaturas médias mensais do verão e do inverno variam entre $315 \mathrm{~mm}$ e $24^{\circ} \mathrm{C}$, e $15 \mathrm{~mm}$ e $19{ }^{\circ} \mathrm{C}$, respectivamente, condizendo com o clima tropical de altitude ou Cwa, segundo o sistema de Köppen (DEL GROSSI, 1993).

Por meio de um levantamento florístico de toda a flora arbórea nativa, Guilherme et al. (1998) caracterizaram fitofisionomicamente as manchas de vegetação nos remanescentes do Parque do Sabiá. Segundo o sistema de classificação da vegetação brasileira proposto pelo IBGE (1991), constatou-se que a área apresenta Floresta Estacional Semidecidual, Savana Florestada (cerradão) e vegetação com influência fluvial, abrangendo tanto a mata de brejo quanto a vereda (campos hidromórficos 
caracterizados pela presença da palmeira arborescente Mauritia flexuosa). Encontram-se, ainda, alguns locais praticamente destituídos da vegetação original, porém restando algumas árvores nativas isoladas e pequenas faixas residuais (leiras), que testemunham a existência de um Cerrado Sensu Stricto ocupando esses trechos há algum tempo. Afloresta estacional possui uma abrupta região de transição com a mata de brejo, que se encontra ao longo de todo o leito do córrego Jataí, e outras duas transições gradativas com duas manchas de cerradões, uma em cada extremidade da floresta (GUILHERME et al., 1998). A vereda ocorre separadamente em outro remanscente.

Há evidências de forte interferência humana no interior dos remanescentes. Principalmente na floresta estacional e nos cerradões, percebe-se a retirada periódica de plantas do sub-bosque por funcionários do Parque, na intenção de manter limpo o seu interior. Contraditoriamente, o lixo acumulado em alguns trechos é visível, onde a ocupação humana é maior devido à presença de mesas e bancos de concreto.

\subsection{Levantamento fitossociológico e análises}

A amostragem compreendeu o período de abril de 1994 a março de 1995. Para a análise da estrutura do componente arbóreo, foi utilizado o método de parcelas de $100 \mathrm{~m}^{2}(10 \times 10 \mathrm{~m})$. Ao todo, foram demarcadas 132 parcelas (1,32 ha), sendo 60 delas alocadas na floresta estacional, 35 no cerradão 1 e 37 no cerradão 2 .

$\mathrm{Na}$ floresta estacional, as parcelas foram alocadas seqüencialmente, formando sete transectos distantes 50 metros um do outro. Cada transecto teve início na borda superior da floresta e terminaram em uma região de menor cota, próxima à transição com a mata de brejo. O número de parcelas de cada transecto variou em função da forma do remanescente florestal. Em ambos os cerradões, as parcelas foram alocadas continuamente, das extremidades em direção à floresta estacional, de forma que quase toda a área fosse amostrada. Embora as faixas de transição dificultem a delimitação florestal, usou-se como critério a caracterização fitofisionômica para estabelecer os limites entre as manchas de vegetação.

Todos os indivíduos arbóreos, com perímetro à altura do peito a $1,30 \mathrm{~m}$ do solo (PAP) $\geq 5 \mathrm{~cm}$, foram amostrados e tiveram material botânico coletado e herborizado. As identificações foram feitas com o auxílio da literatura pertinente, consultas a especialistas e comparações com as coleções do Herbarium Uberlandensis (HUFU), onde o material se encontra depositado. As espécies foram agrupadas nas famílias reconhecidas pelo Angiosperm Phylogeny Group (APG, 2003).

Em todo o levantamento e em cada mancha foram calculados os parâmetros fitossociológicos de densidade, freqüência e dominância relativas, e o valor de importância (VI) de cada espécie, além do índice de diversidade de Shannon (H') e da equabilidade de Pielou (J') (BROWER e ZAR, 1984). Os cálculos foram realizados com o auxílio do programa FITOPAC (SHEPHERD, 1994).

Para analisar as similaridades florística e estrutural entre as três manchas de vegetação estudadas foram empregados os índices de similaridade de Jaccard (qualitativo) e de Morisita (quantitativo), respectivamente (KREBS, 1999). Para cada mancha, os índices de diversidade de Shannon foram comparados aos pares pelo teste t de Hutcheson (ZAR, 1996), retirando-se ao acaso uma subamostra de 35 parcelas por mancha, na intenção de evitar o problema causado por diferentes intensidades amostrais nas comparações entre índices. As distribuições de freqüência da densidade arbórea por classe de diâmetro, nas três manchas, foram comparadas por testes de qui-quadrado $\left(\chi^{2}\right)$. Foram utilizados intervalos de classes diamétricas com amplitudes crescentes, na intenção de compensar o considerável decréscimo na densidade das classes de tamanho superiores e permitir melhor representação das classes de diâmetro maiores e de baixa densidade (OLIVEIRA FILHO et al., 2001).

\section{RESULTADOS E DISCUSSÃO}

Em todo o levantamento foram registrados 2.054 indivíduos, distribuídos em 141 espécies, 99 gêneros e 46 famílias botânicas, resultando em densidade total estimada de 1.556 ind.ha ${ }^{-1} \mathrm{e}$ área basal total estimada de $25,7 \mathrm{~m}^{2} . \mathrm{ha}^{-1}$ (Quadro 1). O índice de diversidade foi estimado em 3,99 nat.ind. ${ }^{-1} \mathrm{e}$ o índice de equabilidade, em 0,81. Quando analisados separadamente, os índices de diversidade foram diferentes entre as três manchas de vegetação, sendo significativamente mais baixo no cerradão 1, significativamente mais alto na floresta estacional e intermediário no cerradão 2 (Quadro 1).

R. Árvore, Viçosa-MG, v.31, n.2, p.329-338, 2007 
Quadro 1 - Informações gerais do levantamento no remanescente florestal do Parque do Sabiá, em Uberlândia, MG Table 1 - General information of the survey in the forest remnant of the Parque do Sabiá, Uberlândia, MG

\begin{tabular}{lcccc}
\hline & Total & Floresta Estacional & Cerradão 1 & Cerradão 2 \\
\hline Área amostrada (hectare) & 1,32 & 0,60 & 0,35 & 0,37 \\
Número de espécies & 141 & 86 & 56 & 78 \\
Número de famílias & 46 & 36 & 32 & 35 \\
Densidade estimada (ind.ha $\left.{ }^{-1}\right)$ & 1556 & 1723 & 1117 & 1700 \\
Área basal estimada $\left(\mathrm{m}^{2} \cdot \mathrm{ha}^{-1}\right)$ & 25,7 & 30,0 & 19,3 & 24,9 \\
Diversidade (H': nat. ind $\left.^{-1}\right)$ & 3,99 & $3,70 \mathrm{a}$ & $2,92 \mathrm{c}$ & $3,45 \mathrm{~b}$ \\
Equabilidade (J') & 0,81 & 0,83 & 0,73 & 0,79 \\
\hline
\end{tabular}

Letras diferentes designam diferenças significativas em testes t para H’ $(P<0,05)$, feitos aos pares, entre floresta estacional, cerradão 1 e cerradão $2(\mathrm{~N}=35)$.

Different letters indicate significant differences in t tests for $H^{\prime}(P<0.05)$ carried out in pairs among semideciduous forest, cerradão 1 and cerradão $2(N=35)$.

Especificamente, o cerradão $1\left(\mathrm{H}^{\prime}=2,92\right)$ apresentou índices de diversidade mais baixos do que aqueles obtidos em outros cerradões dos Estados de Minas Gerais e São Paulo, os quais variaram entre H' = 3,38 (GOMES et al., 2004), H' = 3,40 (GUIMARÃES et al., 2001), H'= 3,47 (PEREIRA-SILVA et al., 2004) e H' = 3,54 (COSTA e ARAÚJO, 2001) nat.ind. ${ }^{-1}$. Os fatores responsáveis pelo baixo índice encontrado no cerradão 1 foram a baixa riqueza florística, aliada ao predomínio de Maprounea guianensis, o que gerou menor equibilidade. Ainda no cerradão 1, foram encontradas espécies arbóreas com alto VI, mas que não ocorrem naturalmente em formações savânicas. São os casos de Peltophorum dubium e Joanesia princeps, as quais são espécies heliófitas, de rápido crescimento, típicas de áreas em estágios iniciais de sucessão ecológica (LORENZI, 1992). A primeira foi registrada também em fragmentos de floresta secundária no Estado do Rio de Janeiro (SANTANA et al., 2004). Por fim, a densidade arbórea foi substancialmente menor. Todos esses fatores associados indicam a ação antrópica no cerradão 1, caracterizando-o como uma formação secundária.

Além do maior índice de diversidade, a floresta estacional também apresentou a maior riqueza florística (86 espécies). Esses dados são compatíveis com outros estudos florísticos e fitossociológicos realizados em florestas estacionais da região de Uberlândia (ARAÚJO eHARIDASAN, 1997; ARAÚJOetal., 1997; GUIMARÃES et al., 2001), onde o número de espécies varia entre 83 e 113 e a diversidade ( $\left.H^{\prime}\right)$, entre 3,7 e 4,1. Além disso, a floresta estacional detém a maior área natural do Parque do Sabiá, possui áreas de transição com as manchas de mata de brejo e cerradão 2 e, ainda, teve área amostrada maior. Tais fatores também devem contribuir para os maiores valores de riqueza e diversidade encontrados.

Fabaceae e Euphorbiaceae apresentaram as maiores densidades e área basal em todo o levantamento, que juntamente com outras oito famílias representaram 71,7 e $79,1 \%$ do total, respectivamente (Figura 1). Fabaceae também apresentou riqueza florística substancialmente maior em todas as três manchas florestais estudadas, com 29 espécies. Esse elevado número de espécies na família Fabaceae ao longo de todas as fisionomias do bioma Cerrado é corroborado tanto em estudos pioneiros (WARMING, 1892) quanto em amplas listagens florísticas atuais (MENDONÇA et al., 1998; CASTRO et al., 1999).

Outras famílias botânicas também mostraram expressivo número de espécies neste estudo, como Myrtaceae (8 espécies)e Rubiaceae, Annonaceae e Vochysiaceae (6 cada). De maneira geral, são famílias bastante representativas em número de espécies nas florestas estacionais do Triângulo Mineiro (ARAÚJO e HARIDASAN, 1997; ARAÚJO et al., 1997), Zona da Mata (SILVA et al., 2004), sul de Minas Gerais (VILELA et al., 2001; MACHADO et al., 2004) e nos cerradões brasileiros (COSTA e ARAÚJO, 2001; PEREIRA-SILVA et al., 2004).

Dez espécies contribuíram com $26,9 \%$ do VI total (Quadro 2). Tapirira obtusa, Hyrtella glandulosa, Cryptocaria aschersoniana e Copaifera langsdorfii destacaram-se, principalmente, devido às elevadas áreas basais e conseqüentes valores de dominância. Virola sebifera, Xylopia aromatica, Casearia grandiflora, Piptocarpha macropoda e Inga vera obtiveram elevados VI, predominantemente por causa da grande abundância 
e frequiência de seus indivíduos em todo o levantamento, embora essas últimas três espécies não tenham ocorrido no cerradão 1. Maprounea guianensis ocorreu tanto na floresta estacional quanto nos cerradões e apresentou os maiores valores relativos de densidade, freqüência, dominância e VI (Quadro 2). Segundo Oliveira Filho e Ratter (2000), a espécie é considerada generalista e heliófita, indicando dependência de luz solar direta para se estabelecer. Isso indica que o remanescente florestal estudado tem passado por um processo de sucessão ecológica, principalmente no cerradão 1 , onde M. guianensis predominou amplamente.

Maprounea guianensis foi ainda a única espécie que ocorreu entre as 10 primeiras em VI, analisando cada mancha florestal em separado. Essa característica indica dissimilaridade estrutural pronunciada entre manchas, especialmente entre floresta estacional e cerradão $1\left(I_{M}=0,17\right)$. Entretanto, as diferenças florísticas foram mais acentuadas ainda. A floresta estacional e o cerradão 1 apresentaram as maiores diferenças $\left(I_{J}=0,15\right)$, enquanto os cerradões apresentaram os maiores valores de similaridade florística e estrutural $\left(I_{\mathrm{J}}=0,43 / \mathrm{I}_{\mathrm{M}}=0,52\right)$. A floresta estacional e o cerradão 2 apresentaram valores intermediários $\left(I_{\mathrm{J}}=0,29\right)$, indicando a presença de um ecótono. Além disso, as 10 espécies com maiores VI no cerradão 2 foram registradas na floresta estacional. Esses valores de similaridade encontrados entre manchas de floresta estacional e cerradões, associados à presença de espécies características de outras fisionomias do bioma Cerrado, indicam que o remanescente florestal do Parque

(A)

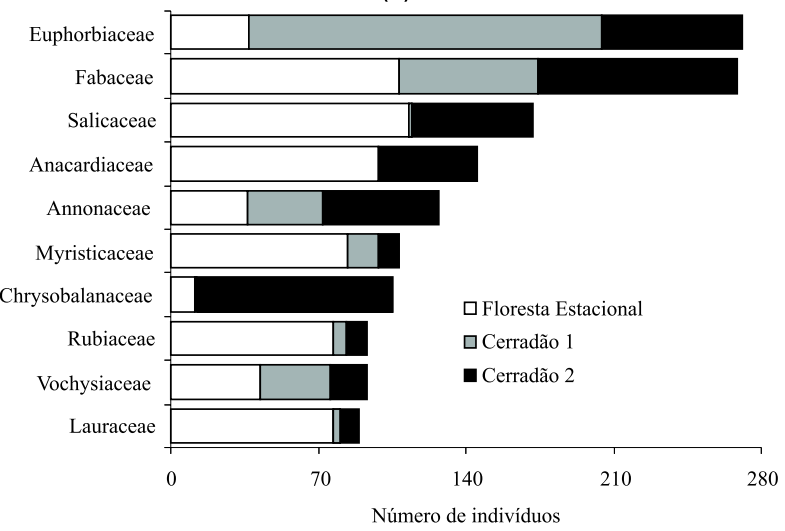

do Sabiá é um bom exemplo de heterogeneidade florística e estrutural da vegetação. Essa heterogeneidade encontrada em formações savânicas enfatiza a necessidade de proteger várias áreas para a preservação de toda a sua biodiversidade, devendo, pois, ser considerada em programas de conservação (FURLEY, 1999).

Diferenças na composição e na estrutura entre as manchas estudadas são notáveis (Quadros 1 e 2). A floresta estacional Cryptocaria aschersoniana teve o maior VI, principalmente devido à presença de indivíduos de grande porte, seguidos de Casearia grandiflora, Virola sebifera, Piptocarpha macropoda e Tapirira obtusa, que apresentaram elevada densidade. Com um total de 56 espécies, o cerradão 1 apresentou baixos valores de densidade e área basal total estimada e teve um predomínio da espécie Maprounea guianensis, com $30,7 \%$ do total de indivíduos registrados. No cerradão 2, Hirtella glandulosa apresentou o maior VI, evidenciando a existência de um solo distrófico nessa fisionomia, já que a espécie é altamente indicadora da presença de solos distróficos e apresenta-se com elevada densidade nos cerradões com essa pedologia (OLIVEIRA FILHO e MARTINS, 1986; FURLEY e RATTER, 1988; SCHIAVINI e ARAÚJO, 1989; MARIMON-JÚNIOR e HARIDASAN, 2005). O cerradão 2 apresentou ainda alto VI de espécies características da mata de brejo e floresta estacional do Parque do Sabiá, como Tapirira obtusa e Inga vera, as quais são representativas dessas formações florestais no bioma Cerrado (MENDONÇA et al., 1998).

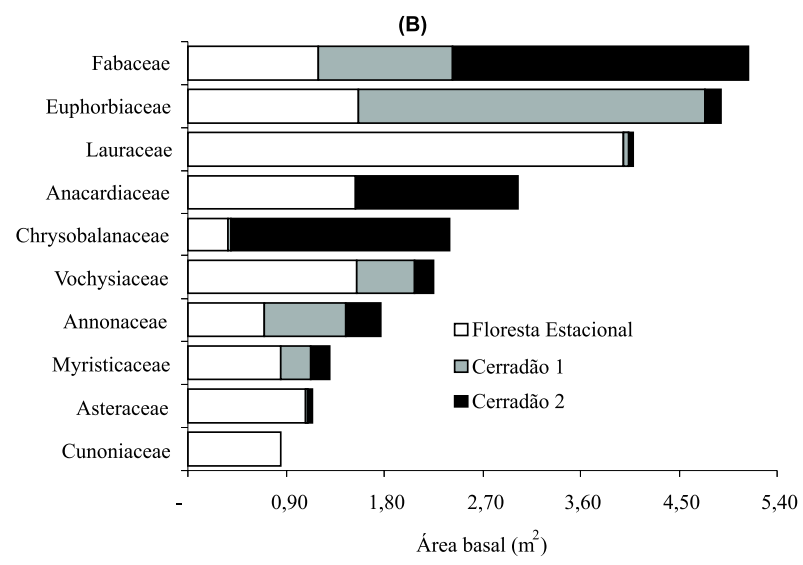

Figura 1 - Dez famílias botânicas mais importantes em número de indivíduos (A) e em área basal (B), no remanescente florestal do Parque do Sabiá, em Uberlândia, MG.

Figure 1 - Ten more important botanic families in number of individuals (A) and basal area (B) in the forest remnant of the Parque do Sabiá, Uberlândia, MG. 
Quadro 2 - Estimativas dos parâmetros quantitativos das espécies arbóreas amostradas no remanescente florestal do Parque do Sabiá, em Uberlândia, MG

Table 2 - Quantitative parameters of the tree species sampled in the forest remnant of the Parque do Sabiá, Uberlândia, $M G$

\begin{tabular}{|c|c|c|c|c|c|c|c|c|c|c|c|c|c|}
\hline \multirow[t]{2}{*}{ Espécies } & \multicolumn{3}{|c|}{$\begin{array}{c}\text { Floresta } \\
\text { Estacional }\end{array}$} & \multicolumn{3}{|c|}{$\begin{array}{c}\text { Cerradão } \\
1\end{array}$} & \multicolumn{3}{|c|}{$\begin{array}{c}\text { Cerradão } \\
2\end{array}$} & \multicolumn{4}{|c|}{ TOTAL } \\
\hline & $\begin{array}{l}\text { DR } \\
(\%)\end{array}$ & $\begin{array}{l}\text { DoR } \\
(\%)\end{array}$ & $\begin{array}{l}\text { FR } \\
(\%)\end{array}$ & $\begin{array}{l}\mathrm{DR} \\
(\%)\end{array}$ & $\begin{array}{l}\text { DoR } \\
(\%)\end{array}$ & $\begin{array}{l}\text { FR } \\
(\%)\end{array}$ & $\begin{array}{l}\text { DR } \\
(\%)\end{array}$ & $\begin{array}{l}\text { DoR } \\
(\%)\end{array}$ & $\begin{array}{l}\text { FR } \\
(\%)\end{array}$ & $\mathrm{N}$ & $\begin{array}{l}\mathrm{AB} \\
\left(\mathrm{m}^{2}\right)\end{array}$ & $\mathrm{P}$ & $\begin{array}{l}\text { VI } \\
(\%)\end{array}$ \\
\hline Maprounea guianensis & 2,9 & 7,0 & 3,6 & 30,7 & 33,1 & 14,4 & 10,3 & 1,2 & 4,6 & 215 & 3,60 & 73 & 26,9 \\
\hline Tapirira marchandii & 6,2 & 6,5 & 3,9 & - & - & - & 6,0 & 14,8 & 3,8 & 102 & 2,53 & 40 & 15,6 \\
\hline Casearia grandiflora & 10,5 & 2,9 & 5,8 & - & - & - & 9,2 & 3,3 & 6,3 & 167 & 0,82 & 62 & 15,5 \\
\hline Hyrtella glandulosa & 0,9 & 1,9 & 1,2 & - & - & - & 13,2 & 20,4 & 8,2 & 92 & 2,22 & 38 & 14,0 \\
\hline Virola sebifera & 8,1 & 4,7 & 5,6 & 3,6 & 4,2 & 3,1 & 1,6 & 1,9 & 1,9 & 108 & 1,31 & 52 & 13,2 \\
\hline Xylopia aromatica & 0,5 & 0,3 & 0,7 & 9,2 & 11,1 & 10,3 & 7,6 & 3,1 & 6,6 & 89 & 1,08 & 52 & 11,6 \\
\hline Cryptocaria aschersoniana & 3,9 & 13,4 & 3,9 & - & - & - & - & - & - & 40 & 2,42 & 26 & 11,1 \\
\hline Piptocarpha macropoda & 6,5 & 6,0 & 4,4 & - & - & - & 2,2 & 0,5 & 2,7 & 81 & 1,13 & 40 & 10,5 \\
\hline Inga vera & 4,9 & 2,5 & 4,0 & - & - & - & 2,1 & 2,3 & 2,2 & 64 & 0,65 & 35 & 7,8 \\
\hline Copaifera langsdorfii & 0,9 & 2,2 & 1,2 & 0,5 & 1,9 & 0,9 & 2,4 & 11,5 & 3,6 & 26 & 1,58 & 23 & 7,8 \\
\hline Qualea grandiflora & 0,1 & 0,0 & 0,2 & 7,7 & 7,0 & 8,1 & 2,5 & 1,8 & 3,0 & 47 & 0,64 & 30 & 6,6 \\
\hline Matayba guianensis & 0,9 & 0,1 & 1,2 & 0,3 & 0,0 & 0,5 & 6,8 & 4,4 & 5,7 & 53 & 0,43 & 30 & 6,2 \\
\hline Ocotea corymbosa & 1,6 & 5,0 & 1,9 & 0,8 & 0,7 & 0,9 & 1,4 & 0,4 & 1,4 & 28 & 0,97 & 20 & 5,8 \\
\hline Callisthene major & 2,5 & 5,7 & 2,2 & - & - & - & - & - & - & 26 & 1,02 & 15 & 5,5 \\
\hline Pera glabrata & 0,7 & 1,7 & 0,9 & 9,7 & 5,2 & 1,8 & 0,3 & 0,5 & 0,3 & 47 & 0,71 & 11 & 5,2 \\
\hline Lamanonia ternata & 1,1 & 6,5 & 1,3 & - & - & - & - & - & - & 11 & 1,17 & 9 & 4,7 \\
\hline Astronium nelson-rosae & 2,8 & 2,0 & 3,4 & - & - & - & 0,5 & 0,0 & 0,8 & 32 & 0,36 & 26 & 4,7 \\
\hline Miconia sellowiana & 2,5 & 2,3 & 3,4 & - & - & - & 0,2 & 0,0 & 0,3 & 27 & 0,42 & 24 & 4,4 \\
\hline Ocotea spixiana & 2,0 & 3,8 & 2,5 & - & - & - & - & - & - & 21 & 0,69 & 17 & 4,4 \\
\hline Amaioua guianensis & 3,9 & 1,4 & 3,1 & - & - & - & - & - & - & 40 & 0,25 & 21 & 4,4 \\
\hline Heisteria ovata & 1,4 & 3,8 & 1,8 & 0,3 & 0,1 & 0,5 & 0,2 & 0,2 & 0,3 & 16 & 0,70 & 14 & 4,0 \\
\hline Schefflera morototoni & 1,1 & 1,6 & 1,5 & 1,5 & 0,7 & 2,2 & 1,0 & 0,5 & 1,6 & 23 & 0,38 & 21 & 3,9 \\
\hline Micropholis venulosa & 2,1 & 2,4 & 2,2 & - & - & - & 0,2 & 0,1 & 0,3 & 23 & 0,43 & 16 & 3,7 \\
\hline Terminalia brasiliensis & 2,2 & 1,1 & 2,5 & - & - & - & 0,3 & 0,5 & 0,6 & 25 & 0,25 & 19 & 3,5 \\
\hline Coussarea hydrangeaefolia & 2,0 & 0,5 & 2,4 & - & - & - & 0,5 & 0,5 & 0,6 & 24 & 0,12 & 18 & 3,0 \\
\hline Dalbergia miscolobium & - & - & - & 2,1 & 0,3 & 3,6 & 2,1 & 1,1 & 3,0 & 21 & 0,12 & 19 & 2,9 \\
\hline Anadenanthera falcata & 0,2 & 0,3 & 0,3 & 1,0 & 4,2 & 1,4 & 0,5 & 2,7 & 0,8 & 9 & 0,59 & 8 & 2,8 \\
\hline Joanesia princeps & - & - & - & 2,3 & 8,7 & 3,1 & - & - & - & 9 & 0,59 & 7 & 2,7 \\
\hline Cheiloclinum cognatum & 2,1 & 0,6 & 2,5 & - & - & - & - & - & - & 22 & 0,10 & 17 & 2,7 \\
\hline Inga laurina & 1,1 & 0,5 & 1,2 & - & - & - & 0,5 & 3,0 & 0,8 & 14 & 0,36 & 11 & 2,6 \\
\hline Plathymenia reticulata & - & - & - & 1,8 & 2,0 & 1,8 & 1,4 & 1,7 & 1,9 & 16 & 0,29 & 11 & 2,5 \\
\hline Pterodon pubescens & 0,1 & 0,0 & 0,2 & 0,5 & 1,2 & 0,9 & 1,8 & 2,5 & 2,2 & 14 & 0,31 & 11 & 2,5 \\
\hline Roupala montana & 0,1 & 0,0 & 0,2 & 0,5 & 0,7 & 0,9 & 1,6 & 1,7 & 2,7 & 13 & 0,21 & 13 & 2,3 \\
\hline Ixora gardneriana & 1,4 & 1,0 & 1,9 & - & - & - & - & - & - & 14 & 0,18 & 13 & 2,3 \\
\hline Annona cacans & 0,4 & 3,2 & 0,6 & - & - & - & - & - & - & 4 & 0,57 & 4 & 2,2 \\
\hline Aspidosperma discolor & 1,5 & 0,6 & 1,9 & - & - & - & - & - & - & 15 & 0,11 & 13 & 2,1 \\
\hline Duguetia lanceolata & 1,6 & 0,3 & 1,9 & - & - & - & - & - & - & 17 & 0,06 & 13 & 2,0 \\
\hline Siparuna guianensis & 1,3 & 0,1 & 1,3 & 0,3 & 0,0 & 0,5 & 0,6 & 0,0 & 0,8 & 18 & 0,03 & 13 & 2,0 \\
\hline Demais espécies & 18,9 & 8,0 & 23,8 & 25,8 & 18,6 & 42,8 & 21 & 17,6 & 30,3 & 415 & 4,26 & 357 & 61,3 \\
\hline
\end{tabular}

$\mathrm{N}=$ número de indivíduos; $\mathrm{AB}=$ área basal $\mathrm{P}=$ número de parcelas; $\mathrm{DR}=$ densidade relativa; $\mathrm{DoR}=$ dominância relativa; $\mathrm{FR}=$ freqüência relativa; e VI = valor de importância. As espécies estão listadas em ordem decrescente de VI total. Ver Guilherme et al. (1998) para autoria das espécies. Espécies com VI <2,0 foram omitidas e inseridas em uma categoria à parte.

$N=$ number of individuals $; A B=$ basal area $; P=$ number of plots $; D R=$ relative density $;$ DoR $=$ relative dominance $; F R=$ relative frequency; and VI = importance value. The species are listed in descending order of total VI. See Guilherme et al. (1998) for species authorship. Species with VI 2.0 were omitted and inserted in a separate class. 
Ribeiro e Walter (1998) consideram que as espécies arbóreas como Hirtella glandulosa, Copaifera langsdorfii, Xylopia aromatica, Pterodon pubescens e Qualea grandiflora são freqüentes no cerradão, e todas essas foram encontradas na floresta estacional e tiveram grande importância no cerradão 2 . Além disso, o cerradão 2 teve densidade arbórea bem próxima daquela da floresta estacional estudada, e o número de espécies foi expressivamente maior do que no cerradão 1 (Quadro 1). Esses fatores em conjunto revelam a existência de áreas transicionais relativamente extensas do cerradão 2 com a mata de brejo e com a floresta estacional. Oliveira Filho e Martins (1986) comentaram que os densos cerradões de Hirtella glandulosa encontrados no Estado do Mato Grosso acompanham córregos no início do seu curso, numa transição para florestas de galeria.

Embora as formações savânicas sejam as fisionomias dominantes no bioma Cerrado, elas se associam a outras formações florestais, formando as regiões de transição savana-floresta, as quais correspondem a um mosaico de aproximadamente 24\% do bioma (SILVA e BATES, 2002). Segundo Ribeiro et al. (1983), a delimitação entre fisionomias de cerradão e de floresta estacional é difícil em alguns casos, mas, empregando-se parâmetros de estrutura e composição florística, pode-se obter uma diferenciação satisfatória, exceto nas áreas de transição entre esses tipos fisionômicos. No Parque do Sabiá, embora desconsideradas para a delimitação geral das fitofisionomias, as áreas transicionais já haviam sido relatadas em estudos florísticos e fitofisionômicos (GUILHERMEet al., 1998)e, agora, foram bem evidenciadas com o estudo da estrutura arbórea das manchas de floresta estacional e cerradões. Portanto, os resultados da estrutura do componente arbóreo das três manchas estudadas indicam que a caracterização fitofisionômica sugerida por Guilherme et al. (1998) está de acordo com as regiões fitoecológicas propostas pelo IBGE (1991), mesmo na presença de faixas de transição.

A distribuição de indivíduos em classes de diâmetro entre as manchas de vegetação em relação ao levantamento total mostrou diferenças significativas através do teste de $\chi^{2}$ (Figura 2). A floresta estacional teve densidade por hectare acima da esperada $(P<0,001)$ nas duas classes de menor tamanho (1,6-4,9e 5,0-8,9 cm), enquanto o cerradão 2 mostrou essa tendência apenas na classe de menor tamanho (1,6-4,9 cm). Entretanto, pôde-se verificar que o cerradão 1 teve um número de indivíduos significativamente menor $(P<0,001)$ nas duas primeiras classes de diâmetro (1,6-4,9 e 5,0-8,9 cm), enquanto o cerradão 2 apresentou essa tendência apenas na classe de 5,0-8,9 cm. A limpeza e a conseqüente remoção de plantas do sub-bosque realizadas pela administração do Parque durante o período do estudo e o constante pisoteio dos visitantes podem comprometer a manutenção de várias espécies do banco de plântulas nas manchas de cerradão, especialmente no cerradão 1 . Além disso, foi observado um número expressivo de árvores mortas em pé ou caídas, além da grande intensidade do bambu do gênero Olyra, que ultimamente domina o estrato inferior em algumas porções do remanescente vegetal, principalmente da floresta estacional (obs. pessoal). Esse impacto sobre a estrutura arbórea afeta os processos naturais de regeneração e estabelecimento, refletindo a necessidade de se estabelecerem propostas de manejo que visem garantir o futuro do remanescente.

Na intenção de oferecer subsídios para um adequado plano de manejo para o Parque do Sabiá, visando à manutenção das características naturais do remanescente florestal estudado, bem como das espécies que o compõem, tornam-se extremamente necessários estudos temporais que levem em consideração a dinâmica das comunidades arbóreas e os processos de invasão de espécies vegetais oportunistas, associadas às alterações nas condições luminosas e edáficas. Além disso, em vista do crescente fluxo de pessoas que procuram o Parque para caminhadas e turismo ecológico, é necessário que seja implantado um extenso programa de educação ambiental voltado para a comunidade escolar e a população local, de forma a conscientiza-las sobre a manutenção desse importante remanescente florestal urbano.

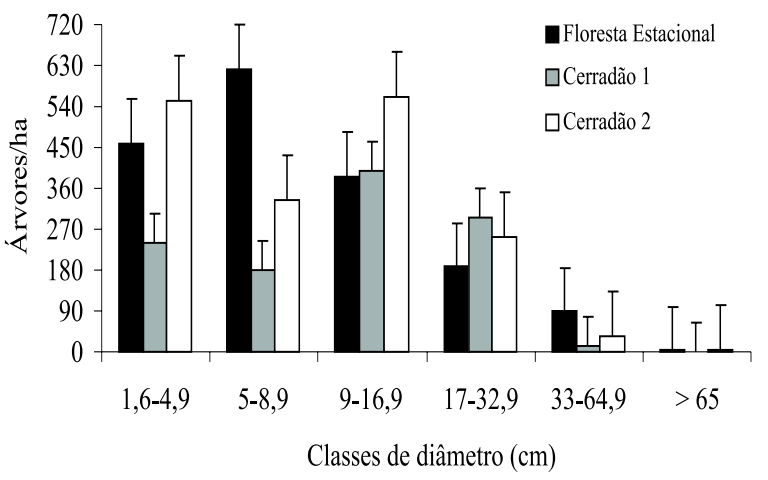

Figura 2 - Distribuição de frequiência por classes de diâmetro no remanescente florestal do Parque do Sabiá, em Uberlândia, MG.

Figure 2 - Frequency distribution per diameter classes in the forest remnant of the Parque do Sabiá, Uberlândia, MG.

R. Árvore, Viçosa-MG, v.31, n.2, p.329-338, 2007 


\section{AGRADECIMENTOS}

Ao CNPq, pela bolsa de Iniciação Científica concedida a F.A.G. Guilherme; e à Andréa Vanini, pela ajuda na coleta de dados de campo.

\section{REFERÊNCIAS}

ANGIOSPERM PHYLOGENY GROUP II. An update of the angiosperm phylogeny group classification for the orders and families of flowering plants: APG II. Botanical Journal of the Linnean Society, v.141, p.399-436, 2003.

ARAÚJO, G.M.; HARIDASAN, M. Estrutura fitossociológica de duas matas mesófilas semidecíduas, em Uberlândia, Triângulo Mineiro. Naturalia, v.22, p.115-129, 1997.

ARAÚJO, G.M. et al. Fitossociologia de um remanescente de mata mesófila semidecídua urbana, Bosque John Kennedy, Araguari, MG, Brasil. Revista Brasileira de Botânica, v.20, n.1, p.67-77, 1997.

BORGES H.B.N.; SHEPHERD, G.J. Flora e estrutura do estrato lenhoso numa comunidade de Cerrado em Santo Antônio do Leverger, MT, Brasil. Revista Brasileira de Botânica, v.28, n.10, p.61-74, 2005.

\section{BROWER, J.E.; ZAR, J.H. Field and} laboratory methods for general ecology. Dubuque: W.M.C. Brown Publication, 1984. 226p.

CASTRO, A.A.J.F. et al. How rich is the flora of Brazilian Cerrados? Annals of the Missouri Botanical Garden, v.86, p.192-224, 1999.

COLE, M.M. Influence of physical factors on the nature and dynamics of forest-savanna boundaries. In: FURLEY, P.A.; PROCTOR, J.; RATTER, J.A. (Ed.). Nature and dynamics of forest-savanna boundaries. London: Chapman e Hall, 1992. p.63-75.

COSTA, A.A.; ARAÚJO, G.M. Comparação da vegetação arbórea de cerradão e de cerrado na Reserva do Panga, Uberlândia, Minas Gerais. Acta Botanica Brasílica, v.15, n.1, p.63-72, 2001.

DEL GROSSI, S.R. A dinâmica climática atual de Uberlândia e suas implicações geomorfológicas. Sociedade \& Natureza, v.5, n.9/10, p.115-120, 1993.

R. Árvore, Viçosa-MG, v.31, n.2, p.329-338, 2007
DISLICH, R.; PIVELLO, V.R. Tree structure and species composition changes in an urban tropical forest fragment (São Paulo, Brazil) during a five-year interval. Boletim de Botânica da Universidade de São Paulo, v.20, p.1-11, 2002.

FURLEY, P.A. The nature and diversity of neotropical savanna vegetation with particular reference to the Brazilian cerrados. Global Ecology and Biogeography, v.8, p.223-241, 1999.

FURLEY, P.A.; RATTER, J.A. The central Brazilian cerrado and their development. Journal of Biogeography, v.15, p.97-108, 1988.

GOMES, B.Z. et al. Estrutura do cerradão e da transição entre cerradão e floresta paludícola num fragmento da International Paper do Brasil Ltda., em Brotas, SP. Revista Brasileira de Botânica, v.27, n.2, p.249-262, 2004.

GUILHERME, F.A.G. et al. Fitofisionomias e a flora lenhosa nativa do Parque do Sabiá, Uberlândia, MG. Daphne, v.8, n.2, p.17-30, 1998.

GUIMARÃES, A.J.M. et al. Características da vegetação e do solo em duas comunidades vegetais contíguas no Triângulo Mineiro. Boletim do Herbário Ezechias Paulo Heringer, v.7, p.113-127, 2001.

HILL, J.L.; CURRAN, P.L. Area, shape and isolation of tropical forest fragments: effects on tree species diversity and implications for conservation. Journal of Biogeography, v.30, p.1391-1403, 2003.

INSTITUTO BRASILEIRODEGEOGRAFIAE ESTATÍSTICA - IBGE. Manual técnico da vegetação brasileira. Série manuais técnicos em geociências. Rio de Janeiro: 1992. 92p.

KREBS, C.J. Ecological methodology. Menlo Park: Addison Wesley Longman, 1999.

LAURANCE, W.F.; BIERREGAARD, R.O. Tropical forest remnants: ecology, management, and conservation of fragmented communities. Chicago: University of Chicago Press, 1997. 632p.

LORENZI, H. Árvores brasileiras. Nova Odessa: Plantarum, 1992. v.1. 281p. 
MACHADO, E.L.M. et al. Análise comparativa da estrutura e flora do compartimento arbóreoarbustivo de um remanescente florestal na Fazenda Beira Lago, Lavras, MG. Revista Árvore, v.28, n.4, p.499-516, 2004.

MARIMON-JÚNIOR, B.H.; HARIDASAN, M. Comparação da vegetação arbórea e características edáficas de um cerradão e um cerrado sensu stricto em áreas adjacentes sobre solo distrófico no leste de Mato Grosso, Brasil. Acta Botanica Brasílica, v.19, n.4, p.913-926, 2005.

MENDONÇA, R.C. et al. Flora vascular do bioma Cerrado. In: SANO, S.M.; ALMEIDA, S.P. (Org.). Cerrado: ambiente e flora. Planaltina: Embrapa, 1998. p.287-556.

\section{OLIVEIRA FILHO, A.T.; MARTINS, F.R.}

Distribuição, caracterização e composição florística das formações vegetais da região de Salgadeira, na Chapada dos Guimarães, MT. Revista Brasileira de Botânica, v.9, p.207-223, 1986.

OLIVEIRA FILHO, A.T.; RATTER, J.A. Padrões florísticos das matas ciliares da região dos cerrados e a evolução das paisagens do Brasil Central durante o Quaternário Tardio. In: Matas ciliares: conservação e recuperação. São Paulo: EDUSP/FAPESP, 2000. p.73-89,

OLIVEIRA FILHO, A.T. et al. Variation in tree community composition and structure with changes in soil properties within a fragment of semideciduous forest in south-eastern Brazil. Edinburgh Journal of Botany, v.58, p.139-158, 2001.

PEREIRA-SILVA, E.F.L. et al. Florística e fitossociologia dos estratos arbustivo e arbóreo de um remanescente de cerradão em uma unidade de conservação do Estado de São Paulo. Revista Brasileira de Botânica, v.27, n.3, p.533-544, 2004.

RIBEIRO, J.F.; WALTER, B.M.T. Fitofisionomias do bioma Cerrado. IN: SANO, S.M.; ALMEIDA, S.P. (Ed.). Cerrado: Ambiente e Flora. Planaltina, Embrapa, 1998. p.89-166.
RIBEIRO, J.F. et al. Os principais tipos fitofisionômicos da região dos cerrados. Boletim de Pesquisa EMBRAPA/ CPAC, v. 21, p.5-28, 1983.

SANTANA, C.A.A. et al. Estrutura horizontal e composição florística de três fragmentos secundários na cidade do Rio de Janeiro. Acta Scientiarum Biological Sciences, v.26, n.4, p.443-451, 2004.

SCHIAVINI, I.; ARAÚJO, G.M. Considerações sobre a vegetação da Reserva Ecológica do Panga (Uberlândia). Sociedade \& Natureza, v.1, n.1, p.61-66, 1989.

SHEPHERD, G.J. FITOPAC I. Manual do usuário. Campinas: Universidade Estadual de Campinas, 1994.93p.

SILVA, J.M.C.; BATES, J.M. Biogeographic patterns and conservation in the south american cerrado: a tropical savanna hotspot.

Bioscience, v.52, n.3, p.225-234, 2002.

SILVA, N.R.S. et al. Composição florística e estrutura de uma floresta estacional semidecidual montana em Viçosa, MG. Revista Árvore, v.28, n.3, p.397-405, 2004.

SMITH, T.B. et al. A role for ecotones in generating rainforest biodiversity. Science, v.276, p.1855-1857, 1997.

VIANA, V.M.; PINHEIRO, L.A.F.V. Conservação da biodiversidade em fragmentos florestais. IPEF, v. 12, p. 25-42, 1998.

VILELA, E.A. et al. Caracterização estrutural de floresta ripária do alto Rio Grande, em Madre de Deus de Minas, MG. Cerne, v.6, n.2, p.41-54, 2001.

WARMing, E. Lagoa Santa. São Paulo: EDUSP/Belo Horizonte: Itatiaia, 1982. 284p. (Original de 1892. Inclui "A vegetação de cerrados brasileiros” por M.G.Ferri, 1892).

ZAR, J.H. Biostatistical analysis. New Jersey: Prentice Hall, 1996. 662p.

R. Árvore, Viçosa-MG, v.31, n.2, p.329-338, 2007 